\title{
A Rapid, Equipment-Free Method for Detecting Phytophthora infestans in the Field Using a Lateral Flow Strip-Based Recombinase Polymerase Amplification Assay
}

\author{
Xinyu Lu, ${ }^{1}$ Ying Zheng, ${ }^{1}$ Fan Zhang, ${ }^{1}$ Jia Yu, ${ }^{1}$ Tingting Dai, ${ }^{2}$ Rongbo Wang, ${ }^{3}$ Yuee Tian, ${ }^{4}$ Heng Xu, ${ }^{1}$ Danyu Shen, ${ }^{1, \dagger}$ \\ and Daolong Dou ${ }^{1}$ \\ ${ }^{1}$ College of Plant Protection, Nanjing Agricultural University, Nanjing 210095, China \\ ${ }^{2}$ College of Forestry, Nanjing Forestry University, Nanjing 210037, China \\ ${ }^{3}$ Institute of Plant Protection, Fujian Academy of Agricultural Sciences, Fuzhou 350013, China \\ ${ }^{4}$ Department of Plant Protection, Henan University of Science and Technology, Luoyang 471000, China
}

\begin{abstract}
Late blight, caused by the oomycete Phytophthora infestans, is a major constraint on the production of potatoes and tomatoes as well as a constant threat to global food security. An early diagnostic tool is important for the effective management of late blight in the field. Here, in combination with a simplified DNA extraction method, we developed a lateral flow strip-based recombinase polymerase amplification (LF-RPA) assay for the rapid, equipment-free detection of $P$. infestans. This assay targets the Ras-related protein $(Y p t 1)$ gene and can be performed over a wide range of temperatures $\left(25\right.$ to $\left.45^{\circ} \mathrm{C}\right)$. All

fg of genomic DNA in optimized conditions. Furthermore, by combining a simplified polyethylene glycol- $\mathrm{NaOH}$ method for extracting DNA from plant samples, the entire LF-RPA assay enabled the detection of $P$. infestans within $30 \mathrm{~min}$ with no specialized equipment When applied to field samples, it successfully detected $P$. infestans in naturally diseased potato plants from eight different fields in China. Therefore, the LF-RPA assay is simple, rapid, and cost-effective and has potential for further development as a kit for diagnosing late blight in resource-limited settings or even on-site.
\end{abstract} $12 P$. infestans isolates yielded positive detection results using the LF-RPA assay, and no cross-reaction occurred with related oomycetes or fungal species. With this assay, the detection limit was 500
Keywords: diagnostics, isothermal amplification, oomycetes, RPA, visualization
Late blight, which is caused by Phytophthora infestans, is very destructive to potato and tomato production globally (Fry 2008; Kamoun 2006). The most famous outbreak of this disease was in Europe, leading to the Irish Potato Famine in 1845 (Fry et al. 2015). Late blight is still a major threat to human food security, causing annual losses of over $\$ 3$ billion worldwide (Fry 2008). China is the largest producer and consumer of potatoes in the world, with 5.8 million cultivated hectares (Birch et al. 2012; Haverkort et al. 2008; Li et al. 2019a). The prevention and control of late blight disease is crucial for potato production.

Because this pathogen has unique biological characteristics, multiple transmission routes, and rapid population divergence, it is difficult to manage and control (Haverkort et al. 2008). Early diagnosis is critical for managing late blight, but it can be challenging for farmers to recognize late blight symptoms. Therefore, rapid and convenient

${ }^{\dagger}$ Corresponding author: D. Y. Shen; shendanyu@ njau.edu.cn

X. Y. Lu and Y. Zheng contributed equally to this work.

Funding: This work was supported by grants from Fundamental Research Funds for the Central Universities (KYT202001 and JCQY201901), and Special Fund for Agro-scientific Research in the Public Interest (201503112).

*The $\boldsymbol{e}$-Xtra logo stands for "electronic extra" and indicates one supplementary figure and two supplementary tables are published online.

The author(s) declare no conflict of interest.

Accepted for publication 8 May 2020.

(C) 2020 The American Phytopathological Society diagnosis methods are required for the control of the disease. Various methods are available for detecting $P$. infestans, such as single-spore isolation of pathogens (Tumwine et al. 2000), conventional polymerase chain reaction (PCR) (Appel et al. 2001; Judelson and Tooley 2000), real-time PCR (Atallah and Stevenson 2006; Hussain et al. 2014), nested PCR (Khan et al. 2017), loop-mediated isothermal amplification (LAMP) (Hansen et al. 2016; Khan et al. 2017), and enzyme-linked immunosorbent assays (Harrison et al. 1990). However, these detection methods have some limitations: they are timeconsuming, labor-intensive, technically complex, and usually have low sensitivity. Thus, the development of new, time-saving, costeffective detection methods to overcome these limits is a topic of increasing interest.

A novel isothermal DNA amplification technology called recombinase polymerase amplification (RPA) was recently developed (Piepenburg et al. 2006). RPA uses three core factors: a recombinase, a DNA-binding protein, and a polymerase. Recombinases pair oligonucleotide primers with the homologous sequence in duplex DNA. Simultaneously, DNA-binding proteins bind to displaced strands of DNA, and the polymerase begins to synthesize complete doublestranded DNA where the primer has bound to the target DNA. The enzyme mixture amplifies the target region within the template exponentially. The RPA assay can be performed within 20 min without thermal cycling at temperatures between 25 and $45^{\circ} \mathrm{C}$ (Kersting et al. 2014; Yang et al. 2017b). RPA amplification products can also be detected using lateral flow strips (Ma et al. 2017). The results are easily read without specialized equipment, suggesting that combining RPA with lateral flow strips (LF-RPA) is suitable for developing a simple, rapid, specific method that can detect plant pathogens in resource-limited settings (Ma et al. 2017; Yang et al. 2017a). The LF-RPA assay has been used to detect diverse pathogens, including bacteria (Du et al. 2018; Ma et al. 2017), viruses (Miao et al. 2019; 
Wang et al. 2019), nematodes (Li et al. 2019b), mycoplasmas (Liu et al. 2019), and rickettsiosis (Qi et al. 2018). However, most of these are human pathogens, and only a few publications have reported the application of RPA to detect plant pathogens. Recently, a LF-RPA method was developed for detecting $P$. capsici in pepper (Yu et al. 2019) and P. sojae in soybean (Dai et al. 2019). In addition, the use of LF-RPA in increasingly large-scale clinical and field applications has led to the need for an effective sample-processing method. Unfortunately, DNA extraction based on the cetyl trimethylammonium bromide method or a plant genomic DNA purification kit is time-consuming and not easily adaptable for practical application (Silva et al. 2018). Chomczynski and Rymaszewski (2006) found an alkaline lysis reagent that allowed a wide variety of biological samples to be used directly in molecular amplification, without further neutralization or DNA isolation steps.

The purpose of this study was to develop a LF-RPA assay, in combination with a simplified DNA extraction method, for the rapid, equipment-free detection of $P$. infestans. To achieve this goal, various elements of LF-RPA including primer specificity and efficiency were analyzed and optimized. Moreover, $P$. infestans cultures and greenhouse-grown potato plants inoculated with $P$. infestans were used for the method development, whereas field potato leaf samples were employed for the method validation.

$P$. infestans isolates (Table 1) were cultured in the dark on rye mixed with $10 \%$ vegetable (V8) juice agar medium at $18^{\circ} \mathrm{C}$. Other
Phytophthora and Pythium species (Table 1) were cultured in the dark on $10 \% \mathrm{~V} 8$ agar medium at $25^{\circ} \mathrm{C}$. Pure cultures of different fungal isolates were routinely maintained on potato dextrose agar medium at $25^{\circ} \mathrm{C}$ in the dark (Tian et al. 2019). The genomic DNA of different isolates and infected samples was extracted using the DNAsecure Plant Kit (DP320) (Tiangen, Beijing, China), according to the manufacturer's instructions. DNA was quantified using the Qubit 3 Fluorometer and Qubit $1 \times$ dsDNA HS Assay Kit (Thermo Fisher Scientific, Wilmington, DE). Ten-fold serial dilutions of $P$. infestans genomic DNA ranging from $50 \mathrm{ng}$ to $500 \mathrm{fg}$ per microliter were used as DNA templates for a subsequent sensitivity test. According to the equation of Wilhelm et al. (2003), the number of $P$. infestans genomes present in $50 \mathrm{ng}$ of genomic DNA was $\sim 1.9 \times 10^{5}$ copies, and $500 \mathrm{fg}$ of DNA contains approximately two genome copies

The target Ras-related protein (Yptl) gene contains sufficient variation across a wide range of Phytophthora species (Schena and Cooke 2006; Schena et al. 2008) and thus was used to detect $P$. infestans in this study. The Yptl sequences of 16 P. infestans isolates and 57 other closely related Phytophthora species were obtained from GenBank. Based on multiplex sequence alignment analysis, three RPA primer pairs were designed for $P$. infestansspecific gene regions (Supplementary Table S1) following the design principles in the RPA guidelines (TwistAmp DNA amplification kits combined instruction manual; TwistDx, Cambridge, U.K.). The probabilities of the formation of hairpins, self-dimers,

Table 1. Isolates tested for specificity of the LF-RPA assay

\begin{tabular}{|c|c|c|c|c|}
\hline Species & Isolate & Origin & Host & LF-RPA ${ }^{a}$ \\
\hline Phytophthora infestans & T30-4 & America & Solanum tuberosum & + \\
\hline P. infestans & 88069 & America & S. tuberosum & + \\
\hline P. infestans & AH-14-03 & China & S. tuberosum & + \\
\hline P. infestans & AH-15-06 & China & S. tuberosum & + \\
\hline P. infestans & AH-16-07 & China & S. tuberosum & + \\
\hline P. infestans & FJ-14-22 & China & S. tuberosum & + \\
\hline P. infestans & FJ-15-02 & China & S. tuberosum & + \\
\hline P. infestans & FJ-16-02 & China & S. tuberosum & + \\
\hline P. infestans & FJ-16-17 & China & S. tuberosum & + \\
\hline P. infestans & HN-16-02 & China & S. tuberosum & + \\
\hline$P$. infestans & B13 & China & S. tuberosum & + \\
\hline P. infestans & NL07434 & China & S. tuberosum & + \\
\hline P. ipomoeae & PIC99167 & England & Ipomoea longipedunculata & - \\
\hline P. ipomoeae & TL85 & England & I. longipedunculata & - \\
\hline P. mirabilis & PIC99114 & England & Mirabilis jalapa & - \\
\hline P. mirabilis & 3010 & England & M. jalapa & - \\
\hline P. sojae & P6497 & China & Glycine $\max$ & - \\
\hline P. sojae & P7064 & China & G. $\max$ & - \\
\hline P. capsici & PC35 & China & Capsicum аппиит & - \\
\hline P. capsici & LT263 & China & C. аппиит & - \\
\hline P. capsici & LT1534 & China & C. аппиит & - \\
\hline P. parasitica & PP025 & China & Nicotiana tabacum & - \\
\hline P. nicotianae & $33 \mathrm{C} 3$ & China & N. tabacum & - \\
\hline P. nicotianae & DB 11032009 & China & N. tabacum & - \\
\hline P. palmivora & P80 & China & Hevea brasiliensis & - \\
\hline P. palmivora & PPM8 & China & H. brasiliensis & - \\
\hline P. cryptogea & St1 & China & Gerbera jamesonii & - \\
\hline P. cryptogea & SIND07 & China & G. jamesonii & - \\
\hline P. cactorum & T506D1 & China & Malus pumila & - \\
\hline P. drechsleri & MG 41-4 & China & Beta vulgaris & - \\
\hline P. megasperma & $\mathrm{P} 45$ & China & Medicago sativa & - \\
\hline Peronophythora litchii & MG 33-3 & China & Litchi chinensis & - \\
\hline Pythium ultimum & CHP13 & China & Solanum lycopersicum & - \\
\hline Py. ultimum & P6 & China & S. lycopersicum & - \\
\hline Py. aphanidermatum & Py15-7 & China & Cucumis sativus & - \\
\hline Py. aphanidermatum & PA1 & China & C. sativus & - \\
\hline Fusarium solani & MRC 2565 & China & Phaseolus vulgaris & - \\
\hline F. solani & NRRL 22678 & China & P. vulgaris & - \\
\hline Rhizoctonia solani & RHRG14 & China & S. tuberosum & - \\
\hline R. solani & Rol222 & China & S. tuberosum & - \\
\hline
\end{tabular}

${ }^{\text {a }}$ LF-RPA = lateral flow strip-based recombinase polymerase amplification; + = positive amplification; and - = negative amplification. 
false priming, and cross-dimers of primers were evaluated using the Multiple Primer Analyzer online website (https://www.thermofisher. $\mathrm{com} /$ ). The designed RPA primers were 35 or $36 \mathrm{nt}$ long, and the amplification product lengths ranged from 212 to 243 bp (Supplementary Table S1). Biotin was added at the $5^{\prime}$ end of the reverse primer for visualization in the lateral flow detection system. A specific internal probe was designed to add a $5^{\prime}$ fluorescein (FAM), an abasic furan (dSpacer), and a C3 spacer (SpC3) to the $3^{\prime}$ end (Supplementary Table S1). Primers and probes were synthesized by Sangon Biotech (Shanghai, China).

The LF-RPA assay was performed according to the quick guide of the TwistAmp nfo kit (TwistDx). Briefly, each reaction contained $29.5 \mu \mathrm{l}$ of rehydration buffer (supplied with the kit), $2.1 \mu \mathrm{l}$ of each primer $(10 \mu \mathrm{M}), 0.6 \mu \mathrm{l}$ of probe $(10 \mu \mathrm{M}), 12.2 \mu \mathrm{l}$ of nuclease-free water (not DEPC-treated) (Thermo Fisher Scientific), and $1 \mu l$ of template. The solution was mixed by vortexing and spinning briefly, and then $2.5 \mu \mathrm{l}$ of $280 \mathrm{mM}$ magnesium acetate (supplied with the kit) was added to each well. Reactions were performed at $39^{\circ} \mathrm{C}$ in a SimpliAmp thermal cycler (model A24812; Thermo Fisher Scientific) for $30 \mathrm{~min}$. For the lateral flow strip (Milenia HybriDetect dipsticks, Milenia Biotec, Giessen, Germany) analysis, the reaction products were diluted 1/20 with HybriDetect assay buffer (supplied in the kit). Strips were placed vertically in $100 \mu l$ of solvent at room temperature for $2 \mathrm{~min}$. If the test and control lines were visible simultaneously, the result was positive; if only the control line was visible, the result was negative. Conventional PCR was performed in a $25-\mu 1$ total volume containing $12.5 \mu \mathrm{l}$ of $2 \times$ Taq Master Mix (Vazyme Biotech, Nanjing, China), $10 \mu \mathrm{M}$ of each primer, $1 \mu \mathrm{l}$ of template DNA, and sterilized $\mathrm{dd}_{2} \mathrm{O}$. All reactions were completed in a SimpliAmp thermal cycler (model A24812; Thermo Fisher Scientific) with an initial 3-min denaturation at $95^{\circ} \mathrm{C}$, followed by 35 cycles of $95^{\circ} \mathrm{C}$ for $15 \mathrm{~s}, 60^{\circ} \mathrm{C}$ for $15 \mathrm{~s}$, and $72^{\circ} \mathrm{C}$ for $15 \mathrm{~s}$, with a final 5 -min extension at $72^{\circ} \mathrm{C}$. The PCR products were then electrophoresed on $2 \%$ gels stained with ethidium bromide. All tests were run under the same conditions and performed in triplicate.

Conventional PCR was initially used to evaluate the sensitivities and specificities of detection with three primer pairs. The result showed that the detection limit of all three primer pairs was $5 \mathrm{pg}$ for conventional PCR (Supplementary Fig. S1A). However, the PiRPA-F2/R2 primer pair was excluded because its product contained obvious primer dimer bands that would affect the amplification efficiency or result in false-positive results. The primer pairs PiRPA-F1/R1 and PiRPA-F3/R3 were used to examine the specificity of conventional PCR, and the results revealed that both primer pairs were specific for $P$. infestans (Supplementary Fig. S1B). PiRPA-F3/R3 was selected for the subsequent RPA assay, and the corresponding PiProb probe was designed. To obtain the optimal primer combination for the LF-RPA assay, the primer combinations PiRPA-F1/R3', PiRPA-F2/R3', and PiRPA-F3/R3' were tested using the RPA reaction system recommended in the TwistAmp RPA nfo kit. The primer combination PiRPA-F2/R3' had the highest sensitivity based on the LF-RPA assay (Fig. 1A). Therefore, this primer combination was selected for further analysis.

The optimum amplification temperature was evaluated by running the LF-RPA assay at different temperatures $(20,25,30,35,40,45$, and $50^{\circ} \mathrm{C}$ ) for $30 \mathrm{~min}$. Results showed that test bands were obvious on the lateral flow strips after 5 min of incubation at temperatures from 25 to $45^{\circ} \mathrm{C}$ (Fig. 1B). The RPA amplification was best at 35 and $40^{\circ} \mathrm{C}$, as shown by the presence of brighter test bands (Fig. 1B). Therefore, the reaction temperature was set to $39^{\circ} \mathrm{C}$ in the subsequent LF-RPA assays. Next, the detection time of the LF-RPA assay was evaluated. RPA amplification was performed at $39^{\circ} \mathrm{C}$ for different amounts of time $(0,5,10,20,30,40$, and $50 \mathrm{~min})$. A faint test band was detected with an amplification time of $10 \mathrm{~min}$, and much brighter bands appeared between 20 and 50 min (Fig. 1C).

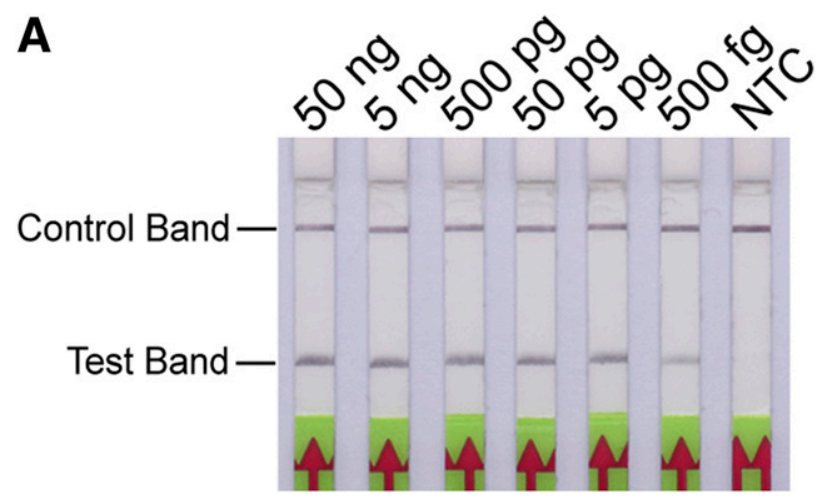

B

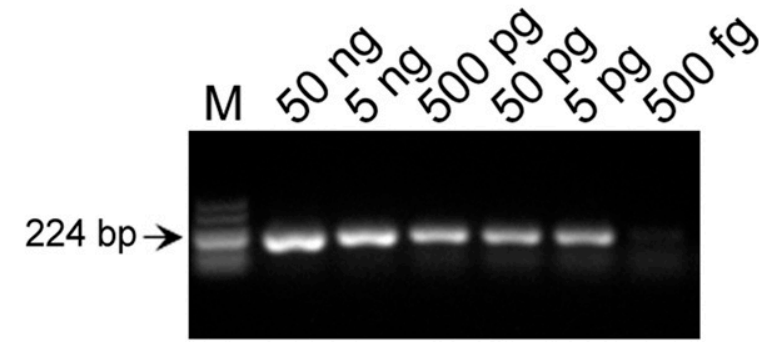

Fig. 2. Evaluation of the sensitivity of the lateral flow strip-based recombinase polymerase amplification (LF-RPA) assay. A, Sensitivity of the LF-RPA assay. B, Sensitivity of the conventional polymerase chain reaction assay. Serial dilutions of Phytophthora infestans T30-4 genomic DNA were used to evaluate the detection limit. NTC $=$ no template control. At least three replicate tests were performed.
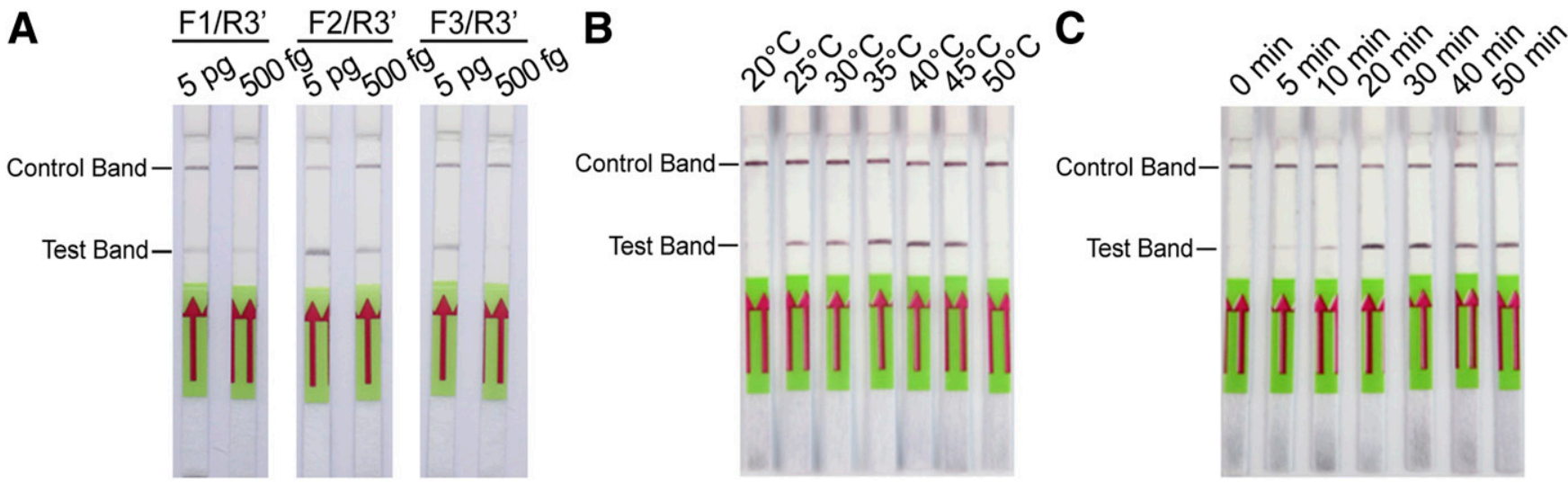

Fig. 1. Optimization of the lateral flow strip-based recombinase polymerase amplification (RPA) assay. A, Evaluation of the optimum primer combination. Different primer combinations are shown at the top of each pair of images. B, Optimization of the RPA amplification temperature. C, Optimization of RPA reaction time. At least three replicate tests were performed. 
Accordingly, the reaction time was set to $20 \mathrm{~min}$ in the subsequent LF-RPA tests.

A total of 12 P. infestans isolates, 20 closely related Phytophthora isolates, four Pythium isolates, and four fungi were tested to evaluate the specificity of the LF-RPA primer using the above conditions. This primer combination yielded positive reactions for the $12 P$. infestans isolates (Table 1), suggesting that this primer combination has the ability to amplify a wide range of $P$. infestans isolates. No amplification signals were obtained for the other related oomycetes or fungal isolates tested. Notably, there was no cross-reactivity with DNA samples from P. mirabilis or P. ipomoeae, which belong to the same $1 \mathrm{c}$ clade as $P$. infestans (Table 1). Therefore, this LFRPA primer combination was highly specific for $P$. infestans. Next, the sensitivity of the LF-RPA assay was estimated using 10-fold serial dilutions of $P$. infestans genomic DNA ranging from $50 \mathrm{ng}$ to $500 \mathrm{fg}$. A faint test band was detected visually for $500 \mathrm{fg}$ of DNA (approximately two genome copies), and the band became brighter with increasing DNA amount (Fig. 2A). Meanwhile, the detection limit was $5 \mathrm{pg}$ of DNA for the conventional PCR assay (Fig. 2B).

To determine the detection practicability of the developed LFRPA assay, the leaf detached assay was performed. The 6-weekold potato plants (cv. Desiree) grown in a greenhouse under the $16-\mathrm{h} 25^{\circ} \mathrm{C} / 8-\mathrm{h} 20^{\circ} \mathrm{C}$ day/night regime were prepared, and the terminal leaflet was cut from each potato plant $(n=6)$, followed by inoculating with $10 \mu \mathrm{l}$ of $P$. infestans T30-4 zoospore suspensions
$(15,000$ sporangia/ml). The inoculated leaflets were placed in the sealed box with wet filter papers, and the petioles were moisturized with wet cotton wools. This experiment was replicated three times. Slight symptoms began to appear at the inoculation site $60 \mathrm{~h}$ postinoculation (Fig. 3A), and then the terminal leaflet was divided into four regions: region I included the inoculation site, whereas region IV was farthest from the inoculation site (Fig. 3A). Trypan blue staining of the terminal leaflet, followed by microscopic examination, revealed that the plant tissues in regions I and II contained visible $P$. infestans mycelia, whereas no obvious mycelia were observed in regions III and IV (Fig. 3A). Next, the total genomic DNA in each of the four regions was extracted and detected by LF-RPA. Leaf tissues from mock-inoculated plants were used as negative controls. As shown in Figure 3B, test bands were clearly observed in regions I, II, and III, but not in region IV or healthy plants. The experiments were repeated three times with consistent results, suggesting that the LFRPA assay can detect $P$. infestans in infected plants.

For the developed LF-RPA method to be useful in the field or lowresource settings, we used a simple polyethylene glycol (PEG)$\mathrm{NaOH}$ to extract total plant leaf DNA using alkaline PEG lysis buffer. This method takes $\sim 5 \mathrm{~min}$ and has been successfully applied to various plant leaf samples (Hwang et al. 2013). In this study, a $3 \times 3-\mathrm{mm}$ specimen of the leaf was ground in a $1.5-\mathrm{ml}$ tube with a TissueLyser (Jingxin Industrial Development, Shanghai, China). The crushed pieces were lysed in $500 \mu \mathrm{l}$ of $6 \%$ PEG200 reagent (SigmaAldrich, Gillingham, U.K.) with $0.08 \% \mathrm{NaOH}$. The tubes were
A

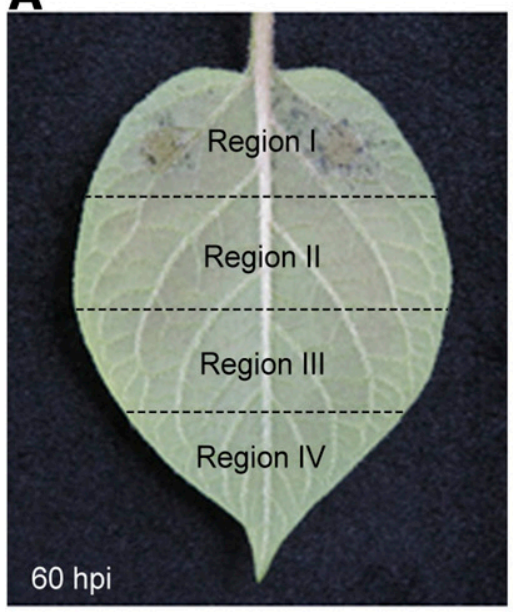

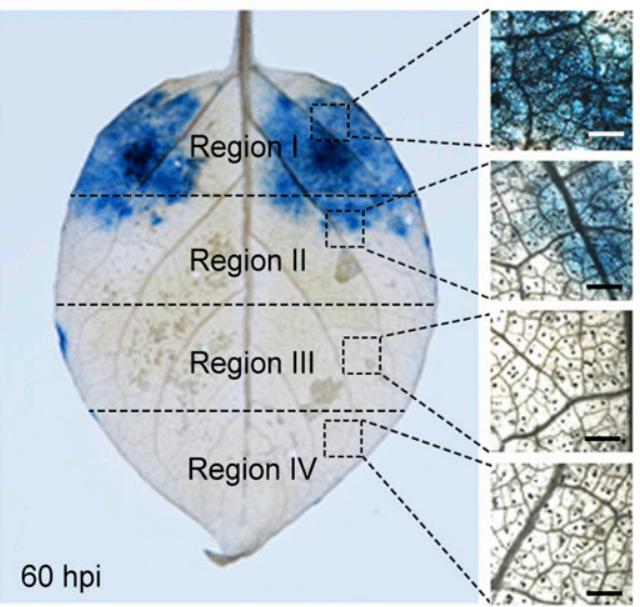

B

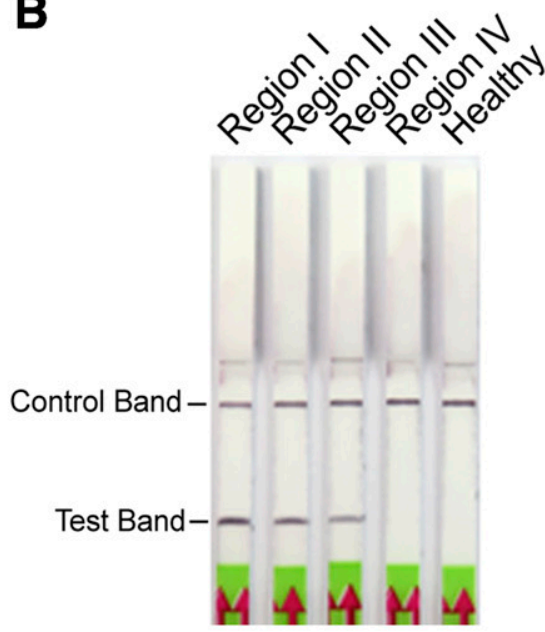

C
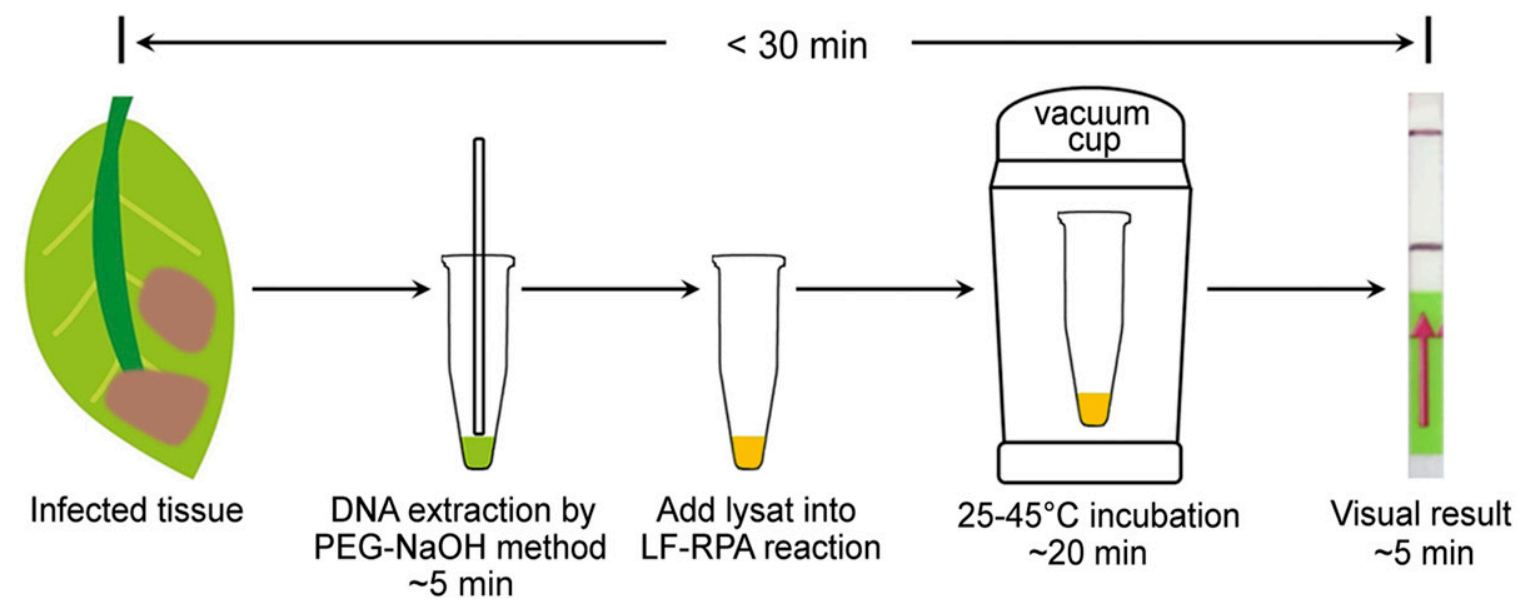

Fig. 3. Early detection of Phytophthora infestans in infected plants. A, Representative potato terminal leaflet infected by $P$. infestans T30-4 zoospores at $60 \mathrm{~h}$ postinoculation (hpi). Artificial division of different areas of the terminal leaflet represents the varying stages of infection. After trypan blue staining of the terminal leaflet, microscopic examination was used to observe $P$. infestans mycelia in each region. Bars indicate $500 \mu \mathrm{m}$. B, Lateral flow strip-based recombinase polymerase amplification (LF-RPA) assay of genomic DNA extracted from different regions of infected potato leaves. Healthy = healthy plant tissues. C, Flow chart of DNA extraction combined with the LF-RPA assay, demonstrating the entire equipment-free detection process, including simplified DNA extraction and LF-RPA assay. 
shaken by hand for $2 \mathrm{~min}$ at room temperature and left standing for $1 \mathrm{~min}$. Thereafter, $2 \mu \mathrm{l}$ of the lysate was added to $50 \mu \mathrm{l}$ of LF-RPA mixture. By utilizing the simplified PEG-NaOH method, the entire LF-RPA assay enabled detection in $30 \mathrm{~min}$ with no specialized equipment (Fig. 3C).

In May 2019, 72 naturally infected potato leaf samples with visible symptoms of late blight were collected from eight different fields in Chongqing ( $n=15$, cultivar Favorita), Guizhou ( $n=22$, cultivar Xuanshu 2), and Hunan ( $n=35$, cultivar Xingjia 2) provinces, China, where potatoes are planted in February (Supplementary Table S2). DNA was extracted from each sample using the abovementioned PEG-NaOH method, and analyzed using both LFRPA and conventional PCR methods. Of the 72 field samples, 52 were identified as positive using both LF-RPA and conventional PCR assays (Supplementary Table S2). Meanwhile, two healthy potato leaf samples collected from each of the eight fields were also tested, and all of these healthy samples produced negative results based on the LF-RPA assay. Therefore, the LF-RPA assay is a simple, accurate method for the practical detection of $P$. infestans in the field.

In conclusion, a novel method for rapid, equipment-free, visual diagnosis of late blight disease was developed in this study. The LF-RPA assay combined with the simplified PEG-NaOH method of DNA extraction could detect $P$. infestans at temperatures from 25 to $45^{\circ} \mathrm{C}$ within $30 \mathrm{~min}$. The amplicons generated bands directly on the lateral flow strip, which can be read by the naked eye. The sensitivity assay revealed that the LF-RPA assay detected a minimum amount of $500 \mathrm{fg}$ of $P$. infestans DNA. Meanwhile, the LF-RPA assay detected crude DNA extracted from plant tissues and enabled the practical diagnosis of late blight in field samples. The LF-RPA assay for $P$. infestans had high sensitivity and specificity, and it could be used as a routine laboratory test or even on-site where expensive diagnostic instruments are not available. Moreover, the developed method can also be applied to other economically important plant pathogens.

\section{Acknowledgments}

We appreciate Professor Suomeng Dong (Nanjing Agricultural University) and Professor Qinghe Chen (Fujian Academy of Agricultural Sciences) for providing Phytophthora isolates used in this study.

\section{Literature Cited}

Appel, R., Adler, N., and Habermeyer, J. 2001. A method for the artificial inoculation of potato tubers with Phytophthora infestans and polymerase chain reaction assay of latently infected sprouts and stems. J. Phytopathol. 149:287-292.

Atallah, Z. K., and Stevenson, W. R. 2006. A methodology to detect and quantify five pathogens causing potato tuber decay using real-time quantitative polymerase chain reaction. Phytopathology 96:1037-1045.

Birch, P. R. J., Bryan, G., Fenton, B., Gilroy, E. M., Hein, I., Jones, J. T., Prashar, A., Taylor, M. A., Torrance, L., and Toth, I. K. 2012. Crops that feed the world 8: Potato: Are the trends of increased global production sustainable? Food Secur. 4:477-508

Chomczynski, P., and Rymaszewski, M. 2006. Alkaline polyethylene glycolbased method for direct PCR from bacteria, eukaryotic tissue samples, and whole blood. Biotechniques 40:454-458.

Dai, T., Yang, X., Hu, T., Jiao, B., Xu, Y., Zheng, X., and Shen, D. 2019. Comparative evaluation of a novel recombinase polymerase amplification-lateral flow dipstick (RPA-LFD) assay, LAMP, conventional PCR, and leaf-disc baiting methods for detection of Phytophthora sojae. Front. Microbiol. 10:1884.

Du, X. J., Zang, Y. X., Liu, H. B., Li, P., and Wang, S. 2018. Recombinase polymerase amplification combined with lateral flow strip for Listeria monocytogenes detection in food. J. Food Sci. 83:1041-1047.

Fry, W. 2008. Phytophthora infestans: The plant (and $R$ gene) destroyer. Mol. Plant Pathol. 9:385-402.

Fry, W. E., Birch, P. R., Judelson, H. S., Grunwald, N. J., Danies, G., Everts, K. L., Gevens, A. J., Gugino, B. K., Johnson, D. A., Johnson, S. B., McGrath, M. T., Myers, K. L., Ristaino, J. B., Roberts, P. D., Secor, G., and Smart, C. D. 2015. Five reasons to consider Phytophthora infestans a reemerging pathogen. Phytopathology 105:966-981.

Hansen, Z. R., Knaus, B. J., Tabima, J. F., Press, C. M., Judelson, H. S., Grunwald, N. J., and Smart, C. D. 2016. Loop-mediated isothermal amplification for detection of the tomato and potato late blight pathogen, Phytophthora infestans. J. Appl. Microbiol. 120:1010-1020.
Harrison, J. G., Barker, H., Lowe, R., and Rees, E. A. 1990. Estimation of amounts of Phytophthora infestans mycelium in leaf tissue by enzyme-linked immunosorbent assay. Plant Pathol. 39:274-277.

Haverkort, A. J., Boonekamp, P. M., Hutten, R., Jacobsen, E., Lotz, L. A. P. Kessel, G. J. T., Visser, R. G. F., and van der Vossen, E. A. G. 2008 Societal costs of late blight in potato and prospects of durable resistance through cisgenic modification. Potato Res. 51:47-57.

Hussain, T., Singh, B. P., and Anwar, F. 2014. A quantitative real time PCR based method for the detection of Phytophthora infestans causing late blight of potato, in infested soil. Saudi J. Biol. Sci. 21:380-386.

Hwang, H., Bae, S.-C., Lee, S., Lee, Y.-H., and Chang, A. 2013. A rapid and simple genotyping method for various plants by direct-PCR. Plant Breed. Biotechnol. 1:290-297.

Judelson, H. S., and Tooley, P. W. 2000. Enhanced polymerase chain reaction methods for detecting and quantifying Phytophthora infestans in plants. Phytopathology 90:1112-1119.

Kamoun, S. 2006. A catalogue of the effector secretome of plant pathogenic oomycetes. Annu. Rev. Phytopathol. 44:41-60.

Kersting, S., Rausch, V., Bier, F. F., and von Nickisch-Rosenegk, M. 2014 Multiplex isothermal solid-phase recombinase polymerase amplification for the specific and fast DNA-based detection of three bacterial pathogens. Microchim. Acta 181:1715-1723.

Khan, M., Li, B., Jiang, Y., Weng, Q., and Chen, Q. 2017. Evaluation of different PCR-based assays and LAMP method for rapid detection of Phytophthora infestans by targeting the Yptl gene. Front. Microbiol. 8:1920.

Li, B., Xu, X., Han, J., Zhang, L., Bian, C., Jin, L., and Liu, J. 2019a. The estimation of crop emergence in potatoes by UAV RGB imagery. Plant Methods 15:15

Li, T. T., Wang, J. L., Zhang, N. Z., Li, W. H., Yan, H. B., Li, L., Jia, W. Z., and Fu, B. Q. 2019b. Rapid and visual detection of Trichinella spp. using a lateral flow strip-based recombinase polymerase amplification (LF-RPA) assay. Front. Cell. Infect. Microbiol. 9:1.

Liu, L., Li, R., Zhang, R., Wang, J., An, Q., Han, Q., Wang, J., and Yuan, W. 2019 Rapid and sensitive detection of Mycoplasma hyopneumoniae by recombinase polymerase amplification assay. J. Microbiol. Methods 159:56-61.

Ma, Q. L., Liu, H. M., Ye, F. D., Xiang, G. X., Shan, W. S., and Xing, W. L. 2017. Rapid and visual detection of Mycobacterium tuberculosis complex using recombinase polymerase amplification combined with lateral flow strips. Mol. Cell. Probes 36:43-49.

Miao, F., Zhang, J., Li, N., Chen, T., Wang, L., Zhang, F., Mi, L., Zhang, J., Wang, S., Wang, Y., Zhou, X., Zhang, Y., Li, M., Zhang, S., and Hu, R. 2019. Rapid and sensitive recombinase polymerase amplification combined with lateral flow strip for detecting African swine fever virus. Front. Microbiol. 10:1004.

Piepenburg, O., Williams, C. H., Stemple, D. L., and Armes, N. A. 2006. DNA detection using recombination proteins. PLoS Biol. 4:e204

Qi, Y., Shao, Y. X., Rao, J. X., Shen, W. P., Yin, Q., Li, X. L., Chen, H. X., Li, J. M., Zeng, W. W., Zheng, S. L., Liu, S. Y., and Li, Y. X. 2018 Development of a rapid and visual detection method for Rickettsia rickettsii combining recombinase polymerase assay with lateral flow test. PLoS One 13:e0207811

Schena, L., and Cooke, D. E. 2006. Assessing the potential of regions of the nuclear and mitochondrial genome to develop a "molecular tool box" for the detection and characterization of Phytophthora species. J. Microbiol. Methods 67:70-85.

Schena, L., Duncan, J. M., and Cooke, D. E. L. 2008. Development and application of a PCR-based 'molecular tool box' for the identification of Phytophthora species damaging forests and natural ecosystems. Plant Pathol. 57:64-75.

Silva, G., Oyekanmi, J., Nkere, C. K., Bomer, M., Kumar, P. L., and Seal, S. E. 2018. Rapid detection of potyviruses from crude plant extracts. Anal. Biochem. 546:17-22

Tian, Y., Che, Z., Sun, D., Yang, Y., Lin, X., Liu, S., Liu, X., and Gao, J. 2019 Resistance identification of tree peony cultivars of different flowering time to gray mold pathogen Botrytis cinerea. HortScience 54:328-330.

Tumwine, J., Frinking, H. D., and Jeger, M. J. 2000. Isolation techniques and cultural media for Phytophthora infestans from tomatoes. Mycologist 14 137-139.

Wang, Z. H., Wang, X. J., and Hou, S. H. 2019. Development of a recombinase polymerase amplification assay with lateral flow dipstick for rapid detection of feline parvovirus. J. Virol. Methods 271:113679.

Wilhelm, J., Pingoud, A., and Hahn, M. 2003. Real-time PCR-based method for the estimation of genome sizes. Nucleic Acids Res. 31:e56.

Yang, Y., Qin, X., Sun, Y., Cong, G., Li, Y., and Zhang, Z. 2017a. Development of isothermal recombinase polymerase amplification assay for rapid detection of porcine circovirus type 2. BioMed Res. Int. 2017:8403642.

Yang, Y., Qin, X., Zhang, X., Zhao, Z., Zhang, W., Zhu, X., Cong, G., Li, Y., and Zhang, Z. 2017b. Development of real-time and lateral flow dipstick recombinase polymerase amplification assays for rapid detection of goatpox virus and sheeppox virus. Virol. J. 14:131

Yu, J., Shen, D., Dai, T., Lu, X., Xu, H., and Dou, D. 2019. Rapid and equipment-free detection of Phytophthora capsici using lateral flow stripbased recombinase polymerase amplification assay. Lett. Appl. Microbiol. 69:64-70. 